\title{
Media and education in the pandemic age of COVID-19
}

\author{
Gianna Cappello, Maria Ranieri
}

This special issue collects a series of interdisciplinary contributions on the impact of COVID-19 with a focus on the intersection point of media/technologies/ education. It includes empirical papers as well as commentaries and best practices on the challenges raised by the health emergency especially in the fields of communication and education sciences. The first section encompasses fourteen scientific articles starting with Journalism and fake news in the Covid-19 era. Perspectives for media education in Italy by Gianna Cappello \& Francesca Rizzuto, which explores the new relationships between the informative cybercascades and the producing of generalized panic highlighting the contribution of media education to active citizenship. It continues with the paper School goes on TV. A research on the quality of an educational program at the time of Covid 19 by Maria Ranieri, Cristina Gaggioli, Alessia Cinotti, Silvia Ercoli, which shifts the focus on the role of public television in ensuring the educational continuity during the pandemic analysing the communication and educational quality of the programme "La Banda dei FuoriClasse" (RAI Gulp, IT). In Home-schooling during the pandemic: A push for digital education in German classrooms?!, Nadine Elstrodt-Wefing \& Ute Ritterfeld present a qualitative study on the impact of remote teaching on teachers' digital change towards the adoption of innovative pedagogies, while Michi S. Fujii, Jana Hüttmann, Nadia Kutscher, \& Henrike Friedrichs-Liesenkötter, authors of Participation?! Educational Challenges for Young Refugees in Times of the COVID-19 Pandemic, show how for certain social groups such as young refugees the experience of distance education increased the risk of exclusion from education. School as educational and socio-cultural hub in the pandemic age of COVID-19 by Manuela Repetto suggests a reflection on the complementary role of schools and local communities to support the educational system, while Teaching and learning in museums in the era of the COVID-19 pandemic by
Marinella Muscarà \& Alessandro Romano explores the role of media and technologies for cultural heritage education in the emergency period. Federico Zannoni with his contribution on University distance teaching during and after the pandemic: impact and perspectives of an emergency measure examines the benefits and the challenges of online lecturing in higher education showing the opportunities that technologies provide for blended learning. Valuations by Spanish university students on online assessment in times of pandemic by Enrique-Javier Díez-Gutiérrez \& Katherine Gajardo Espinoza, investigates students' perceptions of academic assessment practices during the lockdown period stressing that students reclaim greater flexibility in online assessment and formative assessment strategies. Rosa Vegliante \& Sergio Miranda are the authors of Creating tools for the development of visual-spatial intelligence in preschool age: the VIEP-app software model, a playful-educational software model is presented together with evidences on the connection between visual-spatial intelligence and the preschool experience. In (Dis)connected. Pupils, parents, and teachers facing the Covid-19 emergency, Mariagrazia Santagati \& Paolo Barabanti focus on the schoolfamily relationships showing the tensions as well as the opportunities emerged during the school closure due to Coronavirus outbreak. The uncontrolled virus of Infodemia by Igor Scognamiglio \& Diana Salzano analyses the impact of online misinformation about Covid19 disease on the regulation of behaviours and emotions. Another paper with a focus on TV is Educational television in the times of COVID-19. Analysis of the RAI programme "Diario di casa" by Luciano Di Mele \& Erica Della Valle, which proposes a psycho-pedagogical understanding of the programme and an evaluation of the quality of the audio-visual product. Digital Dilemmas and governance of children's digital identities: online communication as an (informal) opportunity for media education by Davide Cino investigates parents' digital dilemmas associated 
with sharenting as an informal learning opportunity to rethink online sharing behavior. The last paper in this section is Kindergarten to the test of LEADs: the experience of the Marche region (IT) where Laura Ceccacci reports data from a study on the main challenges raised by distance education for youngest children, thus covering all ages in the special issue.

The second section on good practices includes five articles which range from online teaching experiences in the areas of Philosophy and Media education (Lia De Marco) to digital inclusive education (Lucia Maffione; Roberta Gianesin), to peer education in higher education (Valentina Pagani) and the use of media by museums in the pandemic age of Covid-19 (Daniela Benedetti). 